\title{
COVID-19 related poor mental health and sleep disorders in rheumatic patients: a citizen science project
}

Francesca Ingegnoli ${ }^{1,2^{*+}} \mathbb{D}$, Massimiliano Buoli ${ }^{3,4+}$, Cristina Posio ${ }^{4}$, Raffaele Di Taranto ${ }^{1,2}$, Alessandro Lo Muscio ${ }^{4}$, Enrico Cumbo ${ }^{1,2}$, Silvia Ostuzzi ${ }^{5}$ and Roberto Caporali ${ }^{1,2}$

\begin{abstract}
Background: Patients with chronic rheumatic diseases (RDs) are more vulnerable and the containment measures related to the COVID-19 pandemic might have severe psychological consequences. We investigated the presence of and risk factors associated with poor mental health, sleep disorders among RDs during the pandemic.

Methods: This cross-sectional Italian citizen science project evaluated the psychological impact of the COVID-19 pandemic in patients with RDs. Between May and September 2020, eleven RD patients' associations sent the survey by using their mailing list and the related webpage and social network. 507 RD patients completed an ad-hoc anonymous online survey including the Perceived Stress Scale (PSS) and Impact Event Scale-Revised (IES-R).

Results: The mean scores on the PSS-10 and the IES-R were 18.1 and 29.7, respectively. Higher PSS scores were associated with younger age $(p<0.01)$, female gender $(p<0.01)$, overweight/obesity $(p=0.01)$, psychiatric pharmacotherapy $(p<0.01)$, and anxiety for loss of income $(p<0.01)$. Higher IES-R scores were associated with female gender $(p<0.01)$, intestinal diseases $(p=0.03)$, anxiety $(p<0.01)$, and health concern $(p<0.01)$. Among 375 patients with inflammatory arthritis, 246 (65.6\%) had trouble staying asleep, 238 (63.5\%) falling asleep, and 112 (29.9\%) had dreams about the pandemic. Older age $(\mathrm{OR}=1.038, \mathrm{Cl} 1.002-1.076)$, psychiatric pharmacotherapy $(\mathrm{OR}=25.819, \mathrm{Cl} 11.465-58.143)$, and COVID infection $(\mathrm{OR}=2.783, \mathrm{Cl} 1.215-6.372)$ were predictive of insomnia during the pandemic.

Conclusions: A considerable COVID-19 related psychosocial burden has been detected in RDs. Different factors were predictive of poor mental health and sleep disorders in these patients. Focused supportive strategies should be implemented to improve the psychological well-being of fragile patients during pandemics.
\end{abstract}

Keywords: Rheumatic diseases, Perceived stress, Post-traumatic stress disorders, COVID-19, Anxiety, Depressive symptoms, Quarantine, Inflammatory arthritis, Connective tissue diseases

\footnotetext{
* Correspondence: francesca.ingegnoli@unimi.it

${ }^{\dagger}$ Francesca Ingegnoli and Massimiliano Buoli contributed equally to this work.

'Division of Clinical Rheumatology, ASST Pini, Milan, Italy

${ }^{2}$ Department of Clinical Sciences \& Community Health, Research Center for Adult and Pediatric Rheumatic Diseases, Università degli Studi di Milano, Piazza Cardinal Ferrari 1, 20122 Milan, Italy

Full list of author information is available at the end of the article
}

(c) The Author(s). 2021 Open Access This article is licensed under a Creative Commons Attribution 4.0 International License, which permits use, sharing, adaptation, distribution and reproduction in any medium or format, as long as you give appropriate credit to the original author(s) and the source, provide a link to the Creative Commons licence, and indicate if changes were made. The images or other third party material in this article are included in the article's Creative Commons. licence, unless indicated otherwise in a credit line to the material. If material is not included in the article's Creative Commons licence and your intended use is not permitted by statutory regulation or exceeds the permitted use, you will need to obtain permission directly from the copyright holder. To view a copy of this licence, visit http://creativecommons.org/licenses/by/4.0/ The Creative Commons Public Domain Dedication waiver (http://creativecommons.org/publicdomain/zero/1.0/) applies to the data made available in this article, unless otherwise stated in a credit line to the data. 


\section{Background}

The coronavirus disease 2019 (COVID-19) pandemic has spread rapidly worldwide. In early 2020, the main European epicenter was in Lombardy (Italy) with more than 600,000 confirmed cases and 30,600 deaths to date, on nearly 10,000.000 inhabitants. Italian Government had to apply unprecedented mitigation policies proclaiming a national lockdown from 9th March to 4th May, leading to significant social and lifestyle changes that affected nearly every aspect of daily life.

Moreover, during the first wave of the pandemic, the healthcare system was overwhelmed by the ongoing outbreak of COVID-19, and this emergence led to unprecedented changes in the clinical management of chronic patients with rheumatic diseases (RDs) with many cancellations or delayed of routine medical appointments [1-5]. RDs are chronic inflammatory disease and RD patients are more vulnerable and sleep disturbance, pain and mood appear to be linked to dysfunctions in circadian rhythms [6-8]; indeed, disease activity, increased pain, fatigue, and psychological factors such as depression and anxiety may negatively affect daily-life activities leading to sleep disorders [9-11]. This latter has a key role in the vicious circle in maintaining chronic pain, mood symptoms, fatigue, and functional impairments creating a dysfunctional cascade characterized by all the major concerns reported by patients with RDs [11-14].

Additionally, a short- and long-term psychosocial burden is one of the relevant consequences of the COVID19 pandemic $[15,16]$. Based on lockdown experiences that were recorded in response to previous epidemics, quarantine measures might have negative psychological effects, including symptoms of post-traumatic stress disorders (PTSD), stress, anxiety, and depression [17-19]. Besides, decreased levels of physical activity and exposure to daylight, as well as changes in routines and mental health concerns, have led to increased incidence of sleep disorders [20]. At present, only scattered data on the psychological impact of the pandemic on Dutch and Turkish patients with RD are available. These studies used different scales to assess the pandemic impact and are not comparable. Thus, the real burden and risk factors of COVID-19 related mental health symptoms on Italian rheumatology patients following the peak of the outbreak is still unknown.

The present study addresses the lack of information on the relationship between COVID-19 and mental health symptoms, sleep disorders and to identify potential factors associated with these concerns. To our knowledge, this study is the first Italian nationwide citizen science project with the active and voluntary participation of associations of patients with chronic rheumatic conditions. The results will be useful to identify RD patients at risk to develop psychiatric symptoms and to implement prevention strategies that can avoid poor mental health in these subjects.

\section{Methods \\ Study design}

The current citizen science cross-sectional study was conducted online to evaluate the psychological impact of the COVID-19 pandemic in Italian patients with RDs.

A structured meeting between a patient representative from the Lombardy Association of patients with RDs (ALOMAR) and medical specialists (rheumatologist and psychiatrist) was convened to discuss the psychological burden related to the pandemic in RDs. Based on support requests received by the patients' association, this online survey called INSIEME, meaning "together" in English was designed. The ethical committee of the University of Milan approved this study (07.05.20-47/20). The survey was for adult patients with RDs (inclusion criteria); it was anonymous, and information could not be verified.

The survey was composed of three parts (supplementary materials). Firstly, participants were all explicitly asked if they were willing to complete the survey and they were informed that their consent would permit them to evaluate the psychological impact of the current pandemic. Then, patients were also asked to self-report demographic, disease characteristics, comorbidities, COVID-19 infection (confirmed by nasal-pharyngeal swab, probable, absent), and their major sources of anxiety. Participants also were asked to indicate the presence of anxiety, depression, or sleep disturbance and related treatment before and after the lockdown period.

In the second part, RD patients were asked to complete the 10-item Perceived Stress Scale (PSS) [21] $[22,23]$ and in the last section the 22-item Impact of Event Scale-Revised (IES-R).

\section{Perceived stress scale}

The 10-item PSS [21] is a validated self-administered questionnaire widely used to assess stress perception during the previous month. Responses to each question are categorized on a 5-point Likert scale from 0 (never) to 4 (very often). The positively worded items of the PSS-10 (4, 5, 7, and 8) were reverse scored. The total scores range from 0 (no stress) to 40 (high stress). Thresholds used in the literature consider the stress level low for scores between 0 and 13; moderate, between 14 and 26; and high, greater than 26 [22, 23].

\section{Impact of event scale-revised}

The 22-item IES- $\mathrm{R}$ is a screening measure used to measure the individual response to a specific traumatic event. It has three subscales (intrusion, avoidance, and hyperarousal), and a total subjective stress score. Participants 
rate the extent to which each item applies to their experiences during the preceding 7 days, from 0 to 4 . The total score ranges from 0 to 88 . The threshold established in the literature is the following: a total score $\geq$ of 33 indicates the probable presence of PTSD [24]. Moreover, we considered items about sleep quality: question 2 (trouble staying asleep), question 15 (trouble falling asleep), and question 20 (dreams about it).

\section{Patient involvement and data collection}

A call for this web-based survey completion was sent using the ALOMAR mailing list and the related webpage and social network, and eleven National patients' associations of RDs among which the National Association of People with RDs (ANMAR) and National Association of People with Rheumatologic and Rare Diseases (APMA $\mathrm{RR})$ contributed to the survey dissemination.

Completion was voluntary, anonymous and participants were not remunerated. The measurement interval took place between May and September 2020, after the first pandemic wave. It was conducted using an internetbased program supported for data protection by the IT service of the Università degli Studi di Milano (UNIMI). The IT service also collected all data and provided a database for the analysis.

The way of collecting data with the dissemination of the questionnaire through social networks and the creation of a specific platform place this project in the field of citizen science studies.

\section{Statistical analysis}

The results of the study were summarized using absolute numbers and percentages and reported according to the GRIPP2 checklist $[25,26]$.

Results were summarized by descriptive statistics using mean, standard deviations, absolute numbers, and percentages. All replies were mandatory, the majority of fields were checkboxes or dropdowns to limit inaccurancies, no missing data were present. Due to the method of dissemination (mailing list, social network, and website), the response rate cannot be determined. Based on the respondents' diagnosis, patients were stratified according to three main groups of RDs (i.e. inflammatory arthritis, connective tissue disease-CTDs-, and primary fibromyalgia). Five patients were excluded, as their diagnosis did not fit the above-mentioned groups.

A linear regression analysis was firstly performed to verify the association between IES-R and PSS total scores. PSS and IES-R total score was compared between groups defined by qualitative variables through one-way analyses of variance (ANOVA) with Bonferroni's posthoc analyses in case of three or more groups; correlation analyses (Pearson's correlation) were performed to analyze the relation between PSS total score and quantitative variables. Subsequently, three linear multivariable regression models for each rating scale were performed considering the statistical significance of the previous analysis: 1) demographic and clinical variables: diagnostic group, age, gender, Lombardy as a region of residency yes/no, disease duration; 2) medical comorbidity variables: COVID-19 symptoms yes/no, hypertension, gastritis, bowel diseases, overweight/obesity; 3) mental health variables: sources of anxiety, depressive symptoms, assumption of medication for psychiatric symptoms before COVID-19, presence of anxiety, current prescription of psychiatric drugs, prescription of psychiatric therapies before COVID-19. These factors were the independent variables while PSS and IES-R scores were the dependent ones. The variables that resulted statistically significant in these three models were inserted in a further final multivariate regression model. The validity of all models was verified by the Durbin-Watson test. The level of statistical significance for all the statistical analyses was set at $p \leq 0.05$.

Concerning sleep disorders, we chose to analyze only the group of patients with inflammatory arthritis as more homogeneous and larger. According to IES-R item $(2-15-20)$ scores, we considered poor sleepers those who reported scores $\geq 1$; moreover, according to patients' answers, we created a new qualitative variable about the presence of sleep disturbances during the pandemic (Yes or No). The two groups identified by this variable were compared by independent-sample t-tests about quantitative variables, while qualitative variables were compared by chi-square tests [x2]. A binary logistic regression model was then performed considering the presence or absence of sleep disorders during the pandemic as a dependent variable and statistically significant variables in the univariate analyses ( $\mathrm{t}$ and $\chi^{2}$ tests) as independent ones. All analyses were performed using SPSS version 26.

\section{Results \\ Sample characteristics}

In total, $507 \mathrm{RD}$ patients completed the survey (Table 1). 375 (73.9\%) patients had inflammatory arthritis (243 rheumatoid arthritis, 76 psoriatic arthritis, 49 ankylosing spondylitis, and 7 Still's disease). 96 (18.9\%) patients had CTDs or systemic vasculitis (22 undifferentiated CTDs, 6 mixed CTDs, 1 polymyositis, 27 systemic sclerosis, 10 Sjögren's syndrome, 23 systemic lupus erythematosus, 5 vasculitis, 2 primary antiphospholipid syndromes). 31 (6.1\%) patients had primary fibromyalgia and 5 osteoarthritis or crystal arthropathies. The RD population was mainly composed of women (417 [82.3\%]), the median (IQR) age was 54 (44-63) years and the median (IQR) disease duration was 10 (5-20) years. Results were obtained from survey responses; no medical records were 
Table 1 Characteristics of 507 respondents

\begin{tabular}{ll}
\hline & Total $(\boldsymbol{n}=\mathbf{5 0 7})$ \\
\hline Gender Female n (\%) & $417(82.2 \%)$ \\
Age yrs., median (Q1, Q3) & $54(44-63)$ \\
Disease duration yrs., median (Q1, Q3) & $10(5-20)$ \\
Diagnosis, $\mathrm{n}(\%)$ & \\
inflammatory arthritis & $375(73.9 \%)$ \\
connective tissue diseases & $96(18.9 \%)$ \\
primary fibromyalgia & $31(6.1 \%)$ \\
miscellaneous & $6(1.1 \%)$ \\
Comorbidities, $\mathrm{n}$ (\%) & \\
Arterial hypertension & $95(18.7 \%)$ \\
Diabetes & $17(3.4 \%)$ \\
Cardiovascular disease & $16(3.2 \%)$ \\
Overweight/obesity & $54(10.7 \%)$ \\
Gastritis & $45(8.9 \%)$ \\
Gastroesophageal reflux disease & $85(16.8 \%)$ \\
Intestinal diseases & $36(7.1 \%)$ \\
Thyroiditis & $70(13.8 \%)$ \\
Ocular diseases & $42(8.2 \%)$ \\
Resident in Lombardy $n$ (\%) & $412(81.3 \%)$ \\
CoviD-19 Infection $\mathrm{n}(\%)$ & $63(12.4 \%)$ \\
\hline
\end{tabular}

Self-reported characteristics of 507 respondents with rheumatic diseases

reviewed. The most frequent comorbidity was gastroesophageal reflux disease, reported by $85(16.8 \%)$ of patients (Table 1).

Among the participants, 412 (81.3\%) lived in Lombardy, the region with the highest rates of infection. 63
(12.4\%) reported an infection of COVID-19 confirmed by positive laboratory test and/or swab or probable (i.e. symptoms compatible with COVID-19).

\section{The severity of mental health outcomes and associated factors}

A small proportion of participants reported psychiatric symptoms before pandemic: depressive symptoms (30, $5.9 \%)$, anxiety (32, 6.3\%), and insomnia (31, 6.1\%). The self-reported use of medication for these symptoms increased from pre- to post-lockdown period: antidepressants $(31[6.1 \%]$ vs $33[6.5 \%])$, anxiolytics $(27[5.3 \%]$ vs $33[6.5 \%])$ and hypnotics (43 [8.5\%] vs 44 [8.7\%]). As shown in Fig. 1, the major sources of anxiety were related to personal and relatives' health (282 [55.6\%]), social isolation (70 [13.8\%]), and financial issues (58 [11.4\%]).

The mean (SD) scores on the PSS-10 for perceived stress and the IES-R for distress for all respondents were $18.1 \pm 8.1$ and $29.7 \pm 17.5$, respectively. The scores of the two rating scales were significantly associated $(\beta=0.65$. $P<0.01)$. Concerning the IES-R subscale scores, the total sample did not show the prominence of one of the three main domains (intrusion, avoidance, and hyperarousal). Patients with fibromyalgia had higher scores in all scales, and subscales compared with other rheumatic diseases (Table 2).

\section{Factors associated with mental health outcomes}

The final multivariate regression model showed that independent variables associated with a higher PSS-10 total score were: female gender $(\beta=0.12, P<0.01)$,

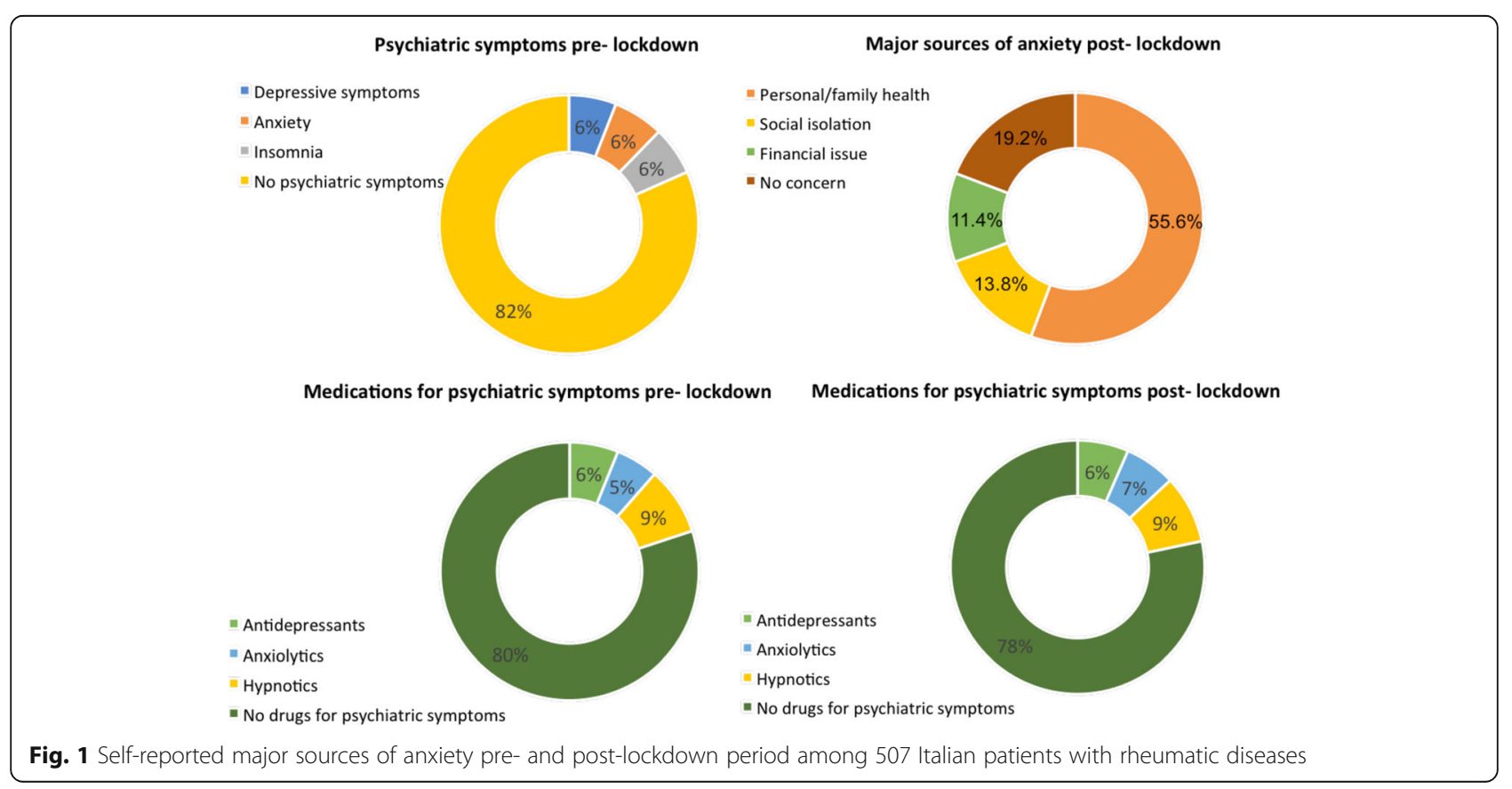


Table 2 Total scores and severity categories of rating scale scores according to diagnostic groups

\begin{tabular}{|c|c|c|c|c|}
\hline & $\begin{array}{l}\text { Inflammatory } \\
\text { arthritis }(n= \\
375)\end{array}$ & $\begin{array}{l}\text { CTDs/ } \\
\text { vasculitis } \\
(n=96)\end{array}$ & $\begin{array}{l}\text { Primary } \\
\text { fibromyalgia } \\
(n=31)\end{array}$ & $\begin{array}{l}\text { Total } \\
(n= \\
502)^{*}\end{array}$ \\
\hline \multicolumn{5}{|l|}{ IES-R score ${ }^{\Delta}$} \\
\hline $\begin{array}{l}\text { Total, } \\
\text { mean } \pm \text { SD }\end{array}$ & $28.7 \pm 17.7$ & $\begin{array}{l}30.5 \pm \\
17.3\end{array}$ & $38.0 \pm 16.1$ & $\begin{array}{l}29.7 \pm \\
17.5\end{array}$ \\
\hline $\begin{array}{l}\text { Normal, n } \\
(\%)\end{array}$ & $234(62.4 \%)$ & $\begin{array}{l}51 \\
(53.1 \%)\end{array}$ & $11(35.5 \%)$ & $\begin{array}{l}296 \\
(59.0 \%)\end{array}$ \\
\hline $\begin{array}{l}\text { Probable } \\
\text { PTSD, n (\%) }\end{array}$ & $141(37.6 \%)$ & $\begin{array}{l}45 \\
(46.9 \%)\end{array}$ & $20(64.5 \%)$ & $\begin{array}{l}206 \\
(41.0 \%)\end{array}$ \\
\hline \multicolumn{5}{|c|}{ IES-R Subscale mean $\pm S D$} \\
\hline intrusion & $10.03 \pm 7.20$ & $\begin{array}{l}11.26 \pm \\
7.23\end{array}$ & $12.77 \pm 7.02$ & $\begin{array}{l}10.4 \pm \\
7.2\end{array}$ \\
\hline avoidance & $10.24 \pm 6.31$ & $\begin{array}{l}10.25 \pm \\
5.84\end{array}$ & $13.06 \pm 6.27$ & $\begin{array}{l}10.4 \pm \\
6.2\end{array}$ \\
\hline hyperarousal & $8.48 \pm 5.94$ & $\begin{array}{l}8.98 \pm \\
6.15\end{array}$ & $12.23 \pm 5.38$ & $\begin{array}{l}8.8 \pm \\
5.9\end{array}$ \\
\hline \multicolumn{5}{|l|}{ PSS-10 score ${ }^{0}$} \\
\hline $\begin{array}{l}\text { Total, } \\
\text { mean } \pm \text { SD }\end{array}$ & $17.4 \pm 8.3$ & $19.8 \pm 7.6$ & $21.6 \pm 6.5$ & $\begin{array}{l}18.1 \pm \\
8.1\end{array}$ \\
\hline $\begin{array}{l}\text { Low }(\leq 13) \\
\text { n (\%) }\end{array}$ & $126(33.6 \%)$ & $\begin{array}{l}23 \\
(24.0 \%)\end{array}$ & $3(9.7 \%)$ & $\begin{array}{l}152 \\
(30.3 \%)\end{array}$ \\
\hline $\begin{array}{l}\text { Moderate } \\
(14-26) n \\
(\%)\end{array}$ & $184(49.1 \%)$ & $\begin{array}{l}58 \\
(60.4 \%)\end{array}$ & $19(61.3 \%)$ & $\begin{array}{l}261 \\
(52.0 \%)\end{array}$ \\
\hline $\begin{array}{l}\text { High ( } \geq 27) \\
\text { n (\%) }\end{array}$ & $65(17.3 \%)$ & $\begin{array}{l}15 \\
(15.6 \%)\end{array}$ & $9(29.0 \%)$ & $\begin{array}{l}89 \\
(17.7 \%)\end{array}$ \\
\hline
\end{tabular}

* 5 of 507 patients had a diagnosis that did not fit with any of the diagnostic groups and were excluded from the analysis

${ }^{\Delta}$ IES-R score $\geq 33$ is indicative of probable Post Traumatic Stress Disorder (PTSD). Difference between diagnostic groups: $\mathrm{X}^{2}=10.25, \mathrm{df}=2, p=0.006$ $\checkmark$ Difference between diagnostic groups: $\mathrm{X}^{2}=11.93, \mathrm{df}=4, p=0.02$

Total scores and severity categories of rating scale scores according to the main rheumatic diagnostic groups

younger age $(\beta=-0.23, P<0.01)$, residence outside Lombardy $(\beta=-0.09, P=0.03)$, presence of overweight/ obesity $(\beta=0.11, P=0.01)$, on-going therapy with psychiatric compounds $(\beta=0.26, P<0.01)$ and anxiety related to loss of incomes $(\beta=0.19, P<0.01)$, see Table 3 .

Regarding IES-R (Table3), the multivariate regression model highlighted that independent variables associated with a higher IES-R total score were female gender $(\beta=$ $0.14, p<0.01)$, living in Lombardy $(\beta=-0.01, p=0.02)$, intestinal diseases $(\beta=0.10, p=0.03)$, anxiety $(\beta=0.19$, $p<0.01)$ and anxiety related to worries about health $(\beta=0.13, p<0.01)$.

\section{Sleep disorders and insomnia predictors in patients with inflammatory arthritis}

Finally, we focused on patients with inflammatory arthritis. Results of questions about sleep are shown in Fig. 2. Patients reporting insomnia had older age $[t=2.844$, $p=.005]$ and higher PSS total score [ $t=3.114, p=.003$ ]. In addition, patients with insomnia had: more
Table 3 Factors significantly associated with mental health outcomes (at least one of the two rating scales) identified by multivariate regression analysis

\begin{tabular}{|c|c|c|c|c|}
\hline & \multicolumn{2}{|c|}{ PSS-10 } & \multicolumn{2}{|l|}{ IES-R } \\
\hline & $\bar{\beta}$ & $p$ & $\bar{\beta}$ & $p$ \\
\hline Gender* & 0.12 & $<0.01$ & 0.14 & $<0.01$ \\
\hline Age & -0.23 & $<0.01$ & -0.09 & 0.06 \\
\hline Region of residence ${ }^{\Delta}$ & -0.09 & 0.03 & -0.10 & 0.02 \\
\hline \multicolumn{5}{|l|}{ Comorbidities } \\
\hline Overweight/obesity ${ }^{\ominus}$ & 0.11 & 0.01 & 0.07 & 0.12 \\
\hline Intestinal diseases ${ }^{\diamond}$ & 0.05 & 0.19 & 0.10 & 0.03 \\
\hline Anxiety disorder ${ }^{\ominus}$ & 0.08 & 0.07 & 0.19 & $<0.01$ \\
\hline \multicolumn{5}{|l|}{ After lockdown } \\
\hline Psychopharmacology ${ }^{\searrow}$ & 0.26 & $<0.01$ & 0.12 & 0.22 \\
\hline Sources of anxiety ${ }^{\omega}$ & 0.19 & $<0.01$ & 0.13 & $<0.01$ \\
\hline
\end{tabular}

*The variable was codified as female $=2 ;$ male $=1$

${ }^{\Delta}$ The variable was codified as $0=$ living in a region different from Lombardy; $1=$ living in Lombardy

${ }^{\circ}$ The variable was codified as $0=$ no; $1=$ yes

${ }^{\omega}$ The variable was codified as $0=$ no source of anxiety; $1=$ health; $2=$ work and finances; 3 = social isolation

$\beta=$ standarizedregression coefficient

IES-R: Impact of Event Scale - Revised; PSS-10: Perceived Stress Scale; ns: not significant

In bold statistically significant $\mathrm{p}$

Factors significantly associated with mental health outcomes (at least one of the two rating scales) identified by multivariate regression analysis

comorbidities $\left(\mathrm{X}^{2}=7.416, \mathrm{df}=1, p=.009\right)$, cardiovascular diseases $\left(X^{2}=5.721, \mathrm{df}=1, p=.039\right)$, depressive symptoms $\left(x^{2}=2.778, \mathrm{df}=1, p=.002\right)$, gastritis $\left(\chi^{2}=4.140\right.$, $\mathrm{df}=1, p=.053)$, bowel diseases $\left(\mathrm{X}^{2}=6.603, \mathrm{df}=1\right.$, $p=.022)$, history of treatment for a psychiatric disorder $\left(\mathrm{X}^{2}=53.907, \mathrm{df}=1, \quad p<.001\right)$, more medications for psychiatric symptoms before COVID-19 $\left(x^{2}=101.446\right.$, $\mathrm{df}=1, p<.001)$ and a more frequent COVID-19 diagnosis $\left(\chi^{2}=6.284, \mathrm{df}=1, p=.018\right)$.

The goodness-of-fit test results (Hosmer and Lemeshow Test: $\left.X^{2}=8.078, \mathrm{df}=8, p=.426\right)$ showed that the binary logistic regression model was reliable, allowing for a correct classification of $90.7 \%$ of the cases. In addition, the model was overall significant (Omnibus test: $\left.\chi^{2}=87.068, \mathrm{df}=10, p<.001\right)$. Age $(\mathrm{OR}=1.038$, $p=.040)$, assumption of medication for psychiatric symptoms before COVID-19 (OR $=25.819$, CI 11.465$58.143)$ and the presence of COVID infection (OR = 2.783 , CI 1.215-6.372) resulted to be predictors of insomnia during the pandemic.

\section{Discussion}

This study revealed a consistent psychological burden among rheumatic patients after confinement during the COVID-19 pandemic in Italy in terms of the high impact of self-reported distress, anxiety, perceived stress, and sleep disorders. Among the identified risk factors, 


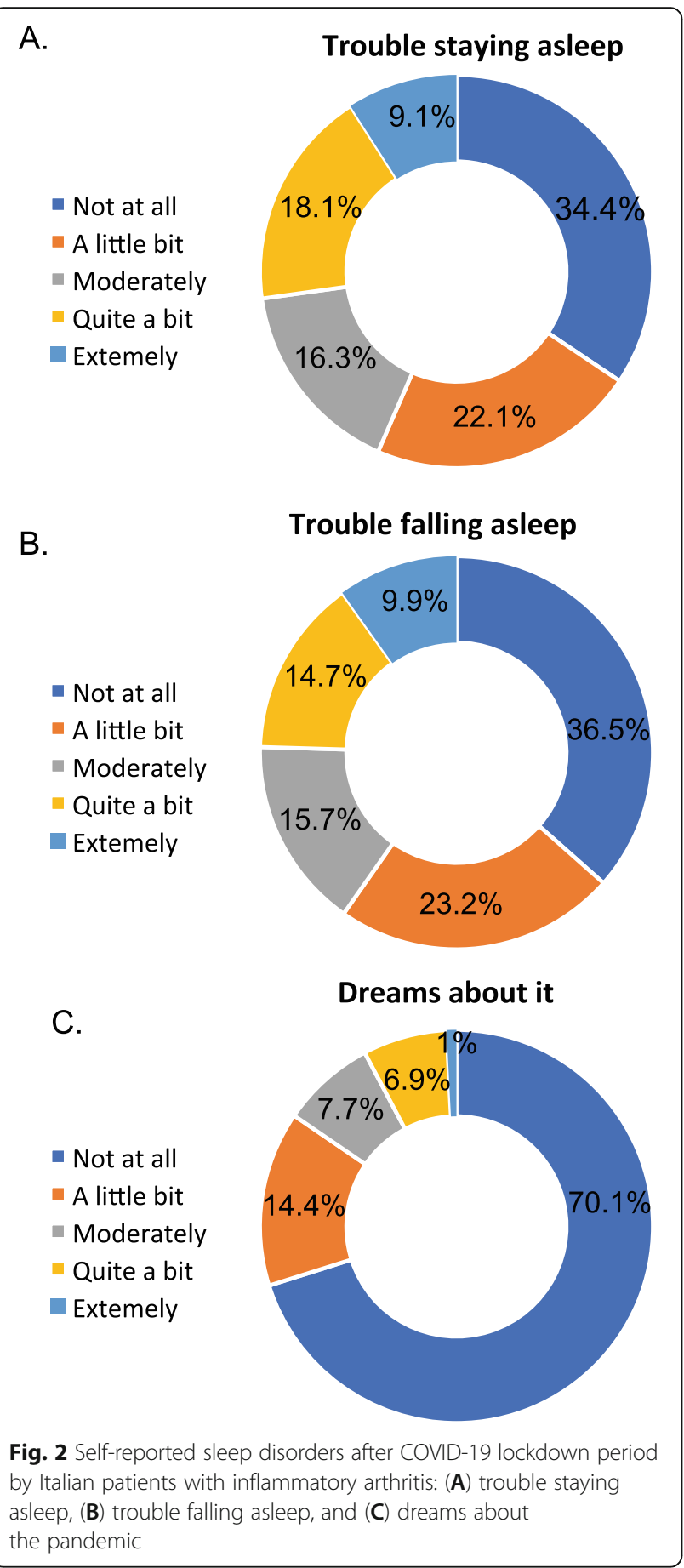

having female gender, younger age, living outside Lombardy, having overweight/obesity, or intestinal diseases, having a history of psychiatric symptoms (e.g. anxiety), and having to experience anxiety for financial or health issues were associated with poor mental health.

According to self-reported psychiatric symptoms and related therapy pre- and post-lockdown, we observed a worsening of symptoms and an increase in the assumption of psychiatric drugs in this vulnerable population.
Our results are consistent with data reported in other cohorts of rheumatic patients during the initial stage of the COVID-19 epidemic [27, 28]. In addition, the impact of trauma was found to significantly influence the severity of stress perceived by patients in agreement with previous reports [24].

In particular, stress and PTSD were perceived more by females. This is not surprising as females and males react to stressful events differently in terms of coping strategies, psychological and biological mechanisms [29-31]. These results are also confirmed by data on the psychological impact of the COVID-19 pandemic on the Italian population [32-34] and Turkish RDs [27].

Moreover, younger adults were found to have higher levels of stress. This is in line with other Italian studies during the COVID-19 outbreak [32, 33, 35], and also with previous studies highlighting that older adults present greater self-control, emotional self-regulation, and better coping strategies compared to younger adults $[36,37]$. A further potential explanation is that younger people might experience higher stress levels because they increased the use of the Internet and social media during the lockdown period [38-40].

The current study found a significant association between overweight/obesity and higher levels of perceived stress, while the presence of intestinal diseases and anxiety disorders were related to PTSD. A recent metaanalysis reported that body mass index is directly associated with perceived stress [41]. Thus, the COVID pandemic might have been perceived as more stressful in the light of poor outcomes associated with the infection in subjects affected by overweight or obesity [42]. Previous studies found PTSD both in inflammatory and functional intestinal diseases [43, 44].

In the context of the COVID-19 pandemic in Italy, the first wave was much more serious in Lombardy than in the other regions. By contrast, our results showed that patients living in regions different from Lombardy had higher PSS-10 and PTSD scores after lockdown. This supports the hypothesis that psychological impact was not only related to direct COVID-19 exposure but also to the media storm that provided a general sense of threat [45]. Furthermore, Lombardy is a highly urbanized region, while in rural areas patients may experience greater difficulty in accessing health facilities in case of emergency [46].

As expected, specific sources of anxiety were related to PSS-10 and PTSD scores. Notably, our data showed that worries about loss of employment and incomes had a greater impact on perceived stress levels after lockdown. These results are consistent with data reported by an Italian study assuming that higher incomes are associated with lower levels of stress [35], while health 
concern is related to psychological distress. The same sources of anxiety were reported in other studies during a pandemic [47-49]. Moreover, these results are consistent with those during quarantines showing that patients with chronic diseases perceived more stress as access to regular medical care and prescriptions were problematic [17].

In the context of the post lockdown phase of the pandemic, while there was a gradual restoration of outpatient services, PTSD was found in $41 \%$ of participants. This appears particularly important for the interpretation of the high rate of severe self-reported distress symptoms. Therefore, it appears to support the concern about the risk of PTSD as the second tsunami of the COVID-19 pandemic [50]. In our data, the main PTSD cluster of symptoms (intrusion, avoidance, and hyperarousal) was balanced without the prominence of none of the domains.

Moreover, sleep disturbances were a relevant concern in patients with inflammatory arthritis, with higher rates of poor sleepers compared to the general Italian population, suggesting that people affected by inflammatory arthritis are more vulnerable to COVID psychological aftermaths $[11,18]$.

Furthermore, our results showed that older patients who had coronavirus infection and were previously treated for psychiatric disorders were at higher risk of developing sleep disorders. Concerning age, this could be explained by age-related changes in circadian rhythms and consequent higher prevalence of insomnia among older people [51]. The previous use of psychiatric compounds in subjects affected by insomnia during the pandemic is not surprising as sleep disturbances are generally observed in patients affected by mental disorders, particularly depression and anxiety [52]. Besides, complaints such as difficulty falling or staying asleep, unsatisfying sleep, irritability, and nightmares are well documented in some anxiety disorders, such as generalized anxiety disorder and PTSD. Finally, our study confirmed COVID-19 infection to be an important contributing factor to the development of insomnia. Indeed, several studies proved that survivors after SARSCoV-2 had negative psychosocial aftermaths; notably, it seems that both immune activation towards the virus and pandemic-related stressors (e.g. isolation, concerns about infecting relatives, financial difficulties) can induce detrimental effects on patients' mental health including poor sleep quality.

It is well established that sleep disruption may worsen arthritis, leading to joint stiffness, pain, weakness, anxiety, depression, and poor outcome [12, 53]. Moreover, impaired sleep may affect work productivity, social functioning, and daily activities, proving to be a considerable psychosocial burden [54].
Some limitations should be considered in the interpretation of these results. First, although the number of respondents is quite large, it represents a part of the RD patients, and self-selection bias may have influenced the results. Second, the cross-sectional design of the study prevents drawing any cause-effect conclusion and the response rate cannot be calculated. Third, although the survey had nationwide dissemination, the respondents were mainly from Lombardy, probably because it was the Italian region most hit during the first wave of the pandemic.

Despite limitations, our findings may have a vested interest for both patients and physicians to support present and post-pandemic interventions related to the COVID-19 pandemic that could be useful for mitigating the psychological impact on more vulnerable patients. Moreover, both stress and PTSD are known triggers for relapse autoimmune diseases; thus, these aspects together with delayed routine medical appointments are inevitably intertwined there is a concern about potential disease flares to which physicians should pay particular attention. Besides, the present findings will be of help to patients' associations that may implement measures for psychological support to alleviate patient distress around COVID-19.

\section{Supplementary Information}

The online version contains supplementary material available at https://doi. org/10.1186/s12888-021-03389-7.

\section{Additional file 1}

\section{Acknowledgements}

We wish to thank the IT service of the University of Milan for their contributions to survey and database integrity, the Lombard Association of Rheumatic Diseases (ALOMAR) for its invaluable contribution to the planning and dissemination the survey, all the Italian associations among which the National Association of People with Rheumatic and Rare Diseases (APMARR) and National Association of People with Rheumatic Diseases (ANMAR) that disseminated the survey through social media. The authors are grateful to all patients for contributing to this project.

\section{Authors' contributions}

FI, MB - Conceptualization; Formal analysis; Funding acquisition; Methodology; Project administration; Supervision; Writing - original draft; $C$, RDT, ALM, EC - Formal analysis; writing original draft- review \& editing. SO, RC - Conceptualization; Supervision; review \& editing. All authors read and approved the final manuscript.

\section{Funding}

This research was supported in part by a Bando Straordinario per Progetti Interdipartimentali (SEED 2019) from the Università degli Studi di Milano.

\section{Availability of data and materials}

The data that support the findings of this study are available from the corresponding author upon reasonable request. 


\section{Declarations}

\section{Ethics approval and consent to participate}

The survey including the informed consent to participate for patients was approved by the ethical committee of the University of Milan (07.05.20-47/ 20). Informed consent was obtained from all the participants at the beginning of the survey, and all methods were carried out in accordance with relevant guidelines and regulations.

\section{Consent for publication}

Not applicable.

\section{Competing interests}

The authors report no conflicts of interest.

\section{Author details}

'Division of Clinical Rheumatology, ASST Pini, Milan, Italy. ${ }^{2}$ Department of Clinical Sciences \& Community Health, Research Center for Adult and Pediatric Rheumatic Diseases, Università degli Studi di Milano, Piazza Cardinal Ferrari 1, 20122 Milan, Italy. ${ }^{3}$ Department of Neurosciences and Mental Health, Fondazione IRCCS Ca'Granda Ospedale Maggiore Policlinico, Milan, Italy. ${ }^{4}$ Department of Pathophysiology and Transplantation, Università degli Studi di Milano, Milan, Italy. ${ }^{5}$ ALOMAR Lombard Association for Rheumatic Diseases, Milan, Italy.

\section{Received: 1 April 2021 Accepted: 22 July 2021}

\section{Published online: 03 August 2021}

\section{References}

1. Favalli EG, Ingegnoli F, Cimaz R, Caporali R. What is the true incidence of COVID-19 in patients with rheumatic diseases? Ann Rheum Dis. 2021;80(2): e18. https://doi.org/10.1136/annrheumdis-2020-217615.

2. Favalli EG, Monti S, Ingegnoli F, Balduzzi S, Caporali R, Montecucco C. Incidence of COVID-19 in patients with rheumatic diseases treated with targeted immunosuppressive drugs: what can we learn from observational data? Arthritis \& rheumatology. 2020;72(10):1600-6. https://doi.org/10.1002/a rt.41388.

3. Maldonado D, Tu E, Mahmood S, Wahezi D, Darapaneni R, Sima N, et al. Medication access difficulty and COVID-related distress are associated with disease flares in rheumatology patients during the COVID-19 pandemic. Arthritis Care Res. 2020. https://doi.org/10.1002/acr.24531.

4. Antony A, Connelly K, De Silva T, Eades L, Tillett W, Ayoub S, et al. Perspectives of patients with rheumatic diseases in the early phase of COVID-19. Arthritis care \& research. 2020;72(9):1189-95. https://doi.org/10.1 002/acr.24347

5. Ingegnoli F, Cincinelli G, Luppino AF, Favalli EG, Orenti A, Boracchi $P$, et al. Ensuring tight control in patients with rheumatoid arthritis treated with targeted therapies during the COVID-19 pandemic using a telehealth strategy. Ann Rheum Dis. 2021;80(Suppl 1):870-1. https://doi.org/10.1136/a nnrheumdis-2021-eular.1104

6. Zaki NFW, Spence DW, BaHammam AS, Pandi-Perumal SR, Cardinali DP, Brown GM. Sleep and circadian rhythms in health and disease: a complex interplay. Eur Arch Psychiatry Clin Neurosci. 2019;269(3):365-6. https://doi. org/10.1007/s00406-018-0866-6.

7. Zaki NFW, Spence DW, BaHammam AS, Pandi-Perumal SR, Cardinali DP, Brown GM. Chronobiological theories of mood disorder. Eur Arch Psychiatry Clin Neurosci. 2018;268(2):107-18. https://doi.org/10.1007/s00406-017-0835-5.

8. Zaki NFW, Spence DW, Subramanian P, Bharti VK, Karthikeyan R, BaHammam AS, et al. Basic chronobiology: what do sleep physicians need to know? Sleep Sci. 2020;13(4):256-66. https://doi.org/10.5935/1984-0063.2 0200026.

9. Wolfe F, Michaud K, Li T. Sleep disturbance in patients with rheumatoid arthritis: evaluation by medical outcomes study and visual analog sleep scales. J Rheumatol. 2006;33(10):1942-51.

10. Westhovens R, Van der Elst K, Matthys A, Tran M, Gilloteau I. Sleep problems in patients with rheumatoid arthritis. J Rheumatol. 2014;41(1):31-40. https:// doi.org/10.3899/jrheum.130430.

11. Ingegnoli F, Schioppo T, Ubiali T, Ostuzzi S, Bollati V, Buoli M, et al. Patient perception of depressive symptoms in rheumatic diseases: a cross-sectional survey. J Clin Rheumatol. 2020; https://doi.org/10.1097/RHU.0000000000001564.
12. Sariyildiz MA, Batmaz I, Bozkurt M, Bez Y, Cetincakmak MG, Yazmalar L, et al. Sleep quality in rheumatoid arthritis: relationship between the disease severity, depression, functional status and the quality of life. Journal of clinical medicine research. 2014;6(1):44-52. https://doi.org/10.4021/jocmr1648w.

13. Hughes M, Chalk A, Sharma P, Dahiya S, Galloway J. A cross-sectional study of sleep and depression in a rheumatoid arthritis population. Clin Rheumatol. 2021;40(4):1299-305. https://doi.org/10.1007/s10067-02005414-8.

14. Morf H, da Rocha C-PG, Vargas-Santos AB, Baerwald C, Seifert O. Impact of clinical and psychological factors associated with depression in patients with rheumatoid arthritis: comparative study between Germany and Brazil. Clin Rheumatol. 2021;40(5):1779-87. https://doi.org/10.1007/s10067-020-054 70-0.

15. Ettman CK, Abdalla SM, Cohen GH, Sampson L, Vivier PM, Galea S. Prevalence of depression symptoms in US adults before and during the COVID-19 pandemic. JAMA Netw Open. 2020;3(9):e2019686. https://doi. org/10.1001/jamanetworkopen.2020.19686.

16. Galea S, Merchant RM, Lurie N. The mental health consequences of COVID19 and physical distancing: the need for prevention and early intervention. JAMA Intern Med. 2020;180(6):817-8. https://doi.org/10.1001/jama internmed.2020.1562.

17. Brooks SK, Webster RK, Smith LE, Woodland L, Wessely S, Greenberg N, et al. The psychological impact of quarantine and how to reduce it: rapid review of the evidence. Lancet. 2020;395(10227):912-20. https://doi.org/10.1016/ S0140-6736(20)30460-8.

18. Casagrande M, Favieri F, Tambelli R, Forte G. The enemy who sealed the world: effects quarantine due to the COVID-19 on sleep quality, anxiety, and psychological distress in the Italian population. Sleep Med. 2020;75:12-20. https://doi.org/10.1016/j.sleep.2020.05.011

19. Zaki NF, Sidiq M, Qasim M, Aranas B, Hakamy A, Ruwais NA, et al. Stress and psychological consequences of COVID-19 on health-care workers. J Nat Sci Med. 2020;3(3):299-307.

20. Werneck AO, Silva DR, Malta DC, Lima MG, Souza-Júnior PRB, Azevedo LO, et al. The mediation role of sleep quality in the association between the incidence of unhealthy movement behaviors during the COVID-19 quarantine and mental health. Sleep Med. 2020;76:10-5. https://doi.org/10.1 016/j.sleep.2020.09.021

21. Cohen S, Kamarck T, Mermelstein R. A global measure of perceived stress. J Health Soc Behav. 1983;24(4):385-96. https://doi.org/10.2307/2136404.

22. Alharbi $\mathrm{H}$, Alshehry A. Perceived stress and coping strategies among ICU nurses in government tertiary hospitals in Saudi Arabia: a cross-sectional study. Ann Saudi Med. 2019;39(1):48-55. https://doi.org/10.5144/0256-4947.2 019.48 .

23. Kim DS, Sung HH, Lee JW, Cho EK. The relationship between perceived stress scale and carotid intima-media thickness using ultrasonography in university students. Korean J Clin Lab Sci. 2017:49(3):308-15. https://doi. org/10.15324/kjcls.2017.49.3.308.

24. Creamer M, Bell R, Failla S. Psychometric properties of the impact of event scale - revised. Behav Res Ther. 2003;41(12):1489-96. https://doi.org/10.1016/ j.brat.2003.07.010.

25. Staniszewska S, Brett J, Simera I, Seers K, Mockford C, Goodlad S, et al. GRIPP2 reporting checklists: tools to improve reporting of patient and public involvement in research. Research involvement and engagement. 2017;3(1):13. https://doi.org/10.1186/s40900-017-0062-2.

26. Staniszewska S, Brett J, Simera I, Seers K, Mockford C, Goodlad S, et al. GRIPP2 reporting checklists: tools to improve reporting of patient and public involvement in research. Bmj. 2017;358:3453.

27. Seyahi E, Poyraz BC, Sut N, Akdogan S, Hamuryudan V. The psychological state and changes in the routine of the patients with rheumatic diseases during the coronavirus disease (COVID-19) outbreak in Turkey: a web-based cross-sectional survey. Rheumatol Int. 2020;40(8):1229-38. https://doi.org/1 0.1007/s00296-020-04626-0.

28. Picchianti Diamanti A, Cattaruzza MS. Psychological Distress in Patients with Autoimmune Arthritis during the COVID-19 Induced Lockdown in Italy. Microorganisms. 2020;8(11):1818. https://doi.org/10.3390/microorga nisms8111818.

29. Verma R, Balhara YP, Gupta CS. Gender differences in stress response: role of developmental and biological determinants. Ind Psychiatry J. 2011:20(1):410. https://doi.org/10.4103/0972-6748.98407.

30. Kajantie E, Phillips DI. The effects of sex and hormonal status on the physiological response to acute psychosocial stress. 
Psychoneuroendocrinology. 2006;31(2):151-78. https://doi.org/10.1016/j. psyneuen.2005.07.002.

31. Kelly MM, Tyrka AR, Price LH, Carpenter LL. Sex differences in the use of coping strategies: predictors of anxiety and depressive symptoms. Depression and anxiety. 2008;25(10):839-46. https://doi.org/10.1002/da.2 0341

32. Mazza C, Ricci E, Biondi S, Colasanti M, Ferracuti S. A Nationwide Survey of Psychological Distress among Italian People during the COVID-19 Pandemic: Immediate Psychological Responses and Associated Factors. Int J Environ Res Public Health. 2020;17(9):3165. https://doi.org/10.3390/ijerph17093165.

33. Rossi R, Socci V, Talevi D, Mensi S, Niolu C, Pacitti F, et al. COVID-19 pandemic and lockdown measures impact on mental health among the general population in Italy. Frontiers in psychiatry. 2020;11:790. https://doi. org/10.3389/fpsyt.2020.00790.

34. Salfi F, Lauriola M, Amicucci G, Corigliano D, Viselli L, Tempesta D, et al. Gender-related time course of sleep disturbances and psychological symptoms during the COVID-19 lockdown: a longitudinal study on the Italian population. Neurobiology of stress. 2020;13:100259. https://doi.org/1 0.1016/j.ynstr.2020.100259.

35. Flesia L, Monaro M, et al. Predicting Perceived Stress Related to the Covid19 Outbreak through Stable Psychological Traits and Machine Learning Models. J Clin Med. 2020;9(10):3350. https://doi.org/10.3390/jcm9103350.

36. Aldwin CM, Sutton KJ, Lachman M. The development of coping resources in adulthood. J Pers. 1996;64(4):837-71. https://doi.org/10.1111/j.1467-6494.1 996.tb00946.x

37. Cohen S, Janicki-Deverts D. Who's stressed? Distributions of psychological stress in the United States in probability samples from 1983, 2006, and 2009. J App Soc Psychol. 2012;42(6):1320-34. https://doi.org/10.1111/j.1 559-1816.2012.00900.x

38. Stijelja S, Mishara BL. COVID-19 and psychological distress-changes in internet searches for mental health issues in New York during the pandemic. JAMA Intern Med. 2020;180(12):1703-6. https://doi.org/10.1001/ja mainternmed.2020.3271.

39. Cellini N, Canale N, et al. Changes in sleep pattern, sense of time and digital media use during COVID-19 lockdown in Italy. J Sleep Res. 2020;29(4): e13074. https://doi.org/10.1111/jsr.13074.

40. Gualano MR, Lo Moro G, Voglino G, et al. Monitoring the impact of COVID19 pandemic on mental health: a public health challenge? Reflection on Italian data. Psychiatr Epidemiol. 2021;56(1):165-7. https://doi.org/10.1007/ s00127-020-01971-0.

41. Tenk J, Mátrai P, Hegyi P, Rostás I, Garami A, Szabó I, et al. Perceived stress correlates with visceral obesity and lipid parameters of the metabolic syndrome: a systematic review and meta-analysis.

Psychoneuroendocrinology. 2018;95:63-73. https://doi.org/10.1016/j. psyneuen.2018.05.014

42. Sanchis-Gomar F, Lavie CJ, Mehra MR, Henry BM, Lippi G. Obesity and outcomes in COVID-19: when an epidemic and pandemic collide. Mayo Clin Proc. 2020;95(7):1445-53. https://doi.org/10.1016/j.mayocp.2020.05.006.

43. Taft TH, Bedell A, Craven MR, Guadagnoli L, Quinton S, Hanauer SB. Initial assessment of post-traumatic stress in a US cohort of inflammatory bowel disease patients. Inflamm Bowel Dis. 2019;25(9):1577-85. https://doi.org/10.1 093/ibd/izz032.

44. Ng QX, Soh AYS, Loke W, Venkatanarayanan N, Lim DY, Yeo WS. Systematic review with meta-analysis: The association between post-traumatic stress disorder and irritable bowel syndrome. J Gastroenterol Hepatol. 2019;34(1): 68-73. https://doi.org/10.1111/jgh.14446.

45. Di Giuseppe M, Zilcha-Mano S, Prout TA, Perry JC, Orrù G, Conversano C Psychological impact of coronavirus disease 2019 among Italians during the first week of lockdown. Front Psychiatr. 2020;1 1:576597. https://doi.org/10.33 89/fpsyt.2020.576597.

46. Newgard CD, Fu R, Bulger E, Hedges JR, Mann NC, Wright DA, et al. Evaluation of rural vs urban trauma patients served by 9-1-1 emergency medical services. JAMA surgery. 2017;152(1):11-8. https://doi.org/10.1001/ja masurg.2016.3329.

47. Michaud K, Wipfler K, Shaw Y, Simon TA, Cornish A, England BR, Ogdie A, Katz P. Experiences of Patients With Rheumatic Diseases in the United States During Early Days of the COVID-19 Pandemic. ACR Open Rheumatol. 2020;2(6):335-43. https://doi.org/10.1002/acr2.11148.

48. Wang C, Pan R, Wan X, Tan Y, Xu L, Ho CS, et al. Immediate psychological responses and associated factors during the initial stage of the 2019 coronavirus disease (COVID-19) epidemic among the general population in
China. Int J Environ Res Public Health. 2020;17(5):1729. https://doi.org/10.33 90/ijerph17051729.

49. Ziadé N, El Kibbi L, Hmamouchi I, Abdulateef N, Halabi H, Hamdi W. Impact of the COVID-19 pandemic on patients with chronic rheumatic diseases: a study in 15 Arab countries. Int J Rheum Dis. 2020;23(11):1550-7. https://doi. org/10.1111/1756-185X.13960.

50. Dutheil F, Mondillon L, Navel V. PTSD as the second tsunami of the SARSCov-2 pandemic. Psychol Med. 2020:1-2. https://doi.org/10.1017/S003329172 0001336.

51. Demartini B, Nisticò V, D'Agostino A, Priori A, Gambini O. Early psychiatric impact of COVID-19 pandemic on the general population and healthcare Workers in Italy: a preliminary study. Frontiers in psychiatry. 2020;11:561345. https://doi.org/10.3389/fpsyt.2020.561345.

52. Mazza MG, De Lorenzo R, Conte C, Poletti S, Vai B, Bollettini I, et al. Anxiety and depression in COVID-19 survivors: role of inflammatory and clinical predictors. Brain Behav Immun. 2020;89:594-600. https://doi.org/10.1016/j. bbi.2020.07.037.

53. Irwin MR, Olmstead R, Carrillo C, Sadeghi N, Fitzgerald JD, Ranganath VK, et al. Sleep loss exacerbates fatigue, depression, and pain in rheumatoid arthritis. Sleep. 2012;35(4):537-43. https://doi.org/10.5665/sleep.1742.

54. Rosekind MR, Gregory KB, Mallis MM, Brandt SL, Seal B, Lerner D. The cost of poor sleep: workplace productivity loss and associated costs. J Occup Environ Med. 2010;52(1):91-8. https://doi.org/10.1097/JOM. ob013e3181c78c30.

\section{Publisher's Note}

Springer Nature remains neutral with regard to jurisdictional claims in published maps and institutional affiliations.
Ready to submit your research? Choose BMC and benefit from:

- fast, convenient online submission

- thorough peer review by experienced researchers in your field

- rapid publication on acceptance

- support for research data, including large and complex data types

- gold Open Access which fosters wider collaboration and increased citations

- maximum visibility for your research: over $100 \mathrm{M}$ website views per year

At BMC, research is always in progress.

Learn more biomedcentral.com/submissions 